\title{
Research for social impact and the contra-ethic of national frameworks
}

\author{
Judith Lovell \\ Northern Institute, Charles Darwin University \\ Judith.Lovell@cdu.edu.au
}

Keywords: ethics, procedure, iteration, remoteness, social impact, Arrernte

\begin{abstract}
Iteration is a factor of the human research ethical clearance through which research and evaluation with humans is undertaken in Australia. In remote community research contexts, iteration has helped us to redress some features of the cultural dissonance that occurs between western and Aboriginal research paradigms and between remote and urban contexts. Without a commensurate ethic of feedback between national programs and remote research settings, the uptake or non-uptake of findings from short-term or rapid-contract research often remain a mystery. The proposition this paper puts forward is for a post-research process whereby research commissioners and administrators provide feedback as to the uptake or not of research findings. This would produce a meta-data, as well as make accessible the rationale for research findings being accepted or rejected. The meta-data would provide baselines for further research, an ongoing record of areas of research and neglect, and assist in the uptake of research knowledge useful at a community level. However, this proposition would require non-partisan support which is highly unlikely to be realised in the current political climate.
\end{abstract}

\section{Human Research Ethics: Protocols, procedures and practices}

Despite being intensely researched, remote Aboriginal community residents' outcomes for health, education, employment, wellbeing and safety fall below the set targets of Australian governments (Australian Government, 2016; Limerick et al., 2014). Evidently, research and evaluation contribute knowledge for the governance and provision of public services, but what knowledge, and how and why, is unclear. There is no formal requirement or system of feedback from research commissioners to research institutions, researchers or community research partners. With so much information and knowledge being produced, what else can human research ethical protocols contribute towards improving remote Aboriginal community outcomes?

All research undertaken in Australia that includes people requires an ethical clearance, which is managed through a university or a government department. A human research ethics committee (HREC) grants a research project clearance when adequate ethical processes and oversight for the research are accepted by the committee. Procedural ethics and ethical practice together describe the process of ethical research and the terms are commonly understood as iteratively linked (Guillemin \& Gillam, 2004). A principal of human research ethics is that research contribute to knowledge that achieves a greater social good. Producing findings through remote Aboriginal community research and evaluation is not enough, despite community-level priorities and the direct benefits of employment, participation and income from community research contract work. The social context of the current policy era has 
been described as "governance by program" (Sulkunen, 2008, p. 75). An era in which policy increasingly frames public services such as welfare as programs, such as active welfare, shaping the relationship between the participant and the state as a contract (Whiteford, 2015). In such an era, if the ethic of social good is to be retained as an ethical principle then recommendations from Aboriginal community research about remote services must inform policy and program designs, and the rationale of such evidence-based policy determination made transparent.

Australian Aboriginal people have been the most researched group on the continent to date (Martin \& Mirraboopa, 2003) and human research ethical protocols have been further adapted from those developed alongside medical advances that used western and medical scientific models. Since the 1990s several reviews have sought to strengthen Aboriginal and Torres Strait Islander ethical research protocols (Dunbar \& Scrimgeour, 2017). The result is that all research which includes Aboriginal participation requires a high-level, formal, ethical clearance in a process which is reviewed by an Indigenous HREC sub-committee, to ensure that Indigenous ethical concerns reflected in the national framework are addressed within the research design (Dunbar \& Scrimgeour, 2017). The national ethical protocols seek to redress cultural dissonance in relation to the Aboriginal health sector (Dunbar \& Scrimgeour, 2017; Martin \& Mirraboopa, 2003), educational sector (Nakata, 2007; Nakata, Nakata, Keech, \& Bolt, 2012), and in the legal interpretation of cultural and intellectual property (Janke, Pitt, \& Herborn, 2013; Orr et al., 2009).

The process of Aboriginal community research in remote settings relies on navigating intersectional power structures and cultural dissonances to undertake practicable and ethical studies. As Kelly et al. (2012) have also observed, research embedded in Aboriginal community participation faces an additional disjunction between what local ethical research entails and the requirements of the contracting clients or other stakeholders that manage, commission or fund the research within the relevant national frameworks for ethics and policy. Considering the diversity between remote settings, there is scope for ethical protocols that further redress cultural dissonance through research partnerships at the community level. At this level research is likely to encounter culturally distinct and fine-grained diversity within community settings as well as between them. The national ethical protocols are intended to maintain the rights of Aboriginal people to self-determine and to project their community and cultural values; but within them, the distinctions of language, culture and geography and the politics of identity are often indiscernible within settings or between them. This reduces the likelihood of the intended values, such as self-determination, being preserved through the national framework. Unless time and money is available for the necessary discussion towards a better understanding of how the research will include and represent a community's value of, and priorities for, self-determination, community level data is unlikely to result in community priority outcomes for local services.

One benefit of Indigenous research knowledge and ethical protocols for non-Indigenous coresearchers is as a process through which the researcher comes to better understand her own involvement with research among collaborators who have an Aboriginal cultural knowledge base, and how this intersects with the espoused and practical human ethical research values. ${ }^{1}$ Field research of remote public service provision with remote community participation is a conduit of information and knowledge about intersectionality, and it highlights the cultural and geographic dissonance that is implicit within the implementation of national frameworks in contemporary remote Aboriginal societies (Austin-Broos, 2001).

1 For more detail about the Indigenous values and ethics requirements for ethical research with Aboriginal and Torres Strait Islander people see Dunbar and Scrimgeour (2017, pp. 64-65); the National Statement (2003, pp. 69-71); and AIATIS Guidelines, (2012, pp. 4-18). 
At the national level, the ethical academic research process is designed so that practice and procedure will ideally inform one another (Guillemin et al., 2016). This iteration of practice, method and procedure is inherent in the design of the human research ethical clearance process. For some research participants, discussing the core values ${ }^{2}$ specific to Aboriginal ethical research protocols in the process of obtaining their informed consent was found to be extremely important. In a longitudinal study those conversations shaped the Informed Consent instruments over time and increased the participation rate in health research described (Dunbar \& Scrimgeour, 2017; Guillemin et al., 2016). But does the imposition of the national framework also reduce the ways that local communities can become engaged in shaping their own ethical research? In another setting and a different research context, the point at which informed consent occurs between Aboriginal participants and co-researchers is less methodically and procedurally reached; in fact the recommended use of the protocol for informed consent can disrupt the research. Paperwork, signatures and formalised records of meetings between outsiders and community elders seldom foster trust, collaboration or participation in remote contexts unless there is a significantly well established relationship (Judd, 2017). There is a point along the trajectory of participation when inter-personal and inter-cultural understandings of one another's roles and of the potential and intent of the work is established, through which the local priorities for the research are determined and "owned" (Lovell, Armstrong, Inkamala, Lechleitner, \& Fisher, 2012).

Participatory Action Research (PAR) (Wadsworth, 2011) is a method of community- and actiondriven research which theoretically seeks to broker mechanisms that result in communitylevel engagement and change. In two cases of remote Aboriginal community research (Lovell, 2017; Lovell et al., 2012) conversational dialogue formed a core function of the research team. With iterative processes embedded into the methodology, the research findings and recommendations could identify and disclose local priorities for safety and wellbeing. The uptake of findings is a mystery: a service provider will have a different rationale than a community member for wanting outcomes; a stakeholder will have a different timeframe and impulse for investing or not in recommendations. Those differences should not be enough to prevent disclosure back to the researchers and community involved.

Not all research undertaken in remote Aboriginal communities occurs with timelines or budgets that can support discussion and dialogue, and much of what has been undertaken in relation to public service program implementation is undertaken in short-term consulting and contract research, or through equally short-term and post-hoc evaluation contracts. Governments' research agendas most directly influence the funding and delivery of services in many central Australian Aboriginal communities. In those scenarios, the timelines for formal ethical clearance are difficult to navigate (6-8 weeks) and certainly can't afford to foster an iterative process at the community level. Yet, contract research is one of the primary conduits of information between remote communities and far distant policy makers. In other words, research that has the least claims to be ethically sound and legitimate (it is short-term, lacks capacity to achieve community engagement or social good outcomes, is poorly funded) has the most significant capacity to impact on and help determine territory, state and federal policy agendas.

The first principle of the Australian Institute of Aboriginal Torres Strait Islander Studies (AIATSIS) guidelines speaks to "recognition of the diversity and uniqueness of peoples, as well as of

2 It is in the spirit of the AIATSIS guidelines that, where research includes Aboriginal people, by extension it includes their communities, custodial lands, belief systems, intellectual property, material and intangible heritage and expression - artefacts, activities and languages - and, in addition, the structures through which people engage their cultures, customs and traditions, and other cultures. The National Statement requires researchers to consider 6 core values regarding engaging Aboriginal people in research. These are: reciprocity, respect, equality, responsibility, survival and protection, and spirit and integrity, and their consideration must be described in a human research ethics application. 
individuals" (AIATSIS, 2012, p. 4). The guidelines are quite specific that, when research findings are extrapolated from one located or cultural group, they are not generalised to apply to all other Aboriginal peoples or communities. Yet, the program framework of social governance disregards the community-level preference or priority, applying the national guidelines only to the act of research, not to the ethical uptake of the knowledge or outcomes of the research process. This is a strong rationale for undertaking co-research with Aboriginal researchers at the community level as well as in institutional academic contexts. It is not evident at which point in the framework of social governance by program that ethical guidelines are replaced with policy guidelines, but it remains evident that policy guidelines retain cultural dissonance within their implementation pathways.

At an institutional level, the aim of redressing cultural dissonance in ethical research and evaluation has been approached by developing specific national Aboriginal and Torres Strait Islander ethical protocols. Aboriginal community research of remote public service delivery is a conduit of information and knowledge about cultural intersections as they operate in remote settings. This conduit highlights the cultural and geographic dissonance that is implicit within the governance by program frameworks that regulate the delivery of those services in those settings. It is implicit in the process of ethical Aboriginal community research that intersectional power structures, their cultural dissonances, and their influence on service delivery will emerge. Two research case studies follow which underline how structural aspects of such dissonance play out in such settings, meanwhile overwhelming local priorities and capacity.

\section{Arrernte community research cases}

Ntaria (Hermannsburg) has attracted government funding for programs, program evaluation and research through consecutive Closing the Gap (CTG) policies since 2008. Ltyentye Apurte (Santa Teresa) was largely without extra Closing the Gap program initiatives until 2015. Ntaria was a nominated Growth Town (Northern Territory Government, 2009-2012) and a Remote Operational Centre (Australian Government, 2009-2012). Ltyentye Apurte was given neither status. Changes to the Local Government Act in 2008 saw both communities' transition from local Aboriginal Community Government Authorities into operational centres of the MacDonnell Shire Council. The 2016 Australian Bureau of Statistics Census recorded that Ntaria had a population of approximately 533 people (Australian Bureau of Statistics, 2016a), who reside in the community and at 20 homelands in the five Arrernte estates that make up the land trust. Ltyentye Apurte had a population of 502 people (Australian Bureau of Statistics, 2016b), with two homelands; one inside and one outside the Santa Teresa Land Trust. Ntaria is located along a highly promoted and sealed tourist route between Uluru and Alice Springs; Ltyentye Apurte is located along the Binns track, a lesser travelled tourist four-wheel drive track networking from Western Australia through to Queensland. Both communities are within 1.5 hours drive of Alice Springs.

The average educational attainment and the percentage of people employed full or part time as recorded by the 2016 census are slightly higher at Ltyentye Apurte than at Ntaria, and the median age at Ltyentye Apurte (23) is younger than at Ntaria (28). Household median weekly income at Ltyentye Apurte was $\$ 878$, with an average household of 4.9 people; at Ntaria the household median weekly income was $\$ 778$, with an average household of 4.6 people. The high-level census data do not reveal any gains in employment or education in the community in which the major government policy and funding investment has occurred (Ntaria). It may be that retrospectively Ntaria was further behind with services and participation than Ltyentye Apurte and has since caught up through the higher levels of CTG programming. Yet the same high-level statistics from the 2006 census, a pre CTG era census, does not support that 
conclusion. In 2006 the median age at Ntaria was slightly younger (19) than at Ltyentye Apurte (21). Household median income at Ntaria was $\$ 900$, with an average household of 7.1 people; at Ltyentye Apurte the median income was $\$ 559$ in a household of 5.3 people. The equivalence of income per person in household is slightly higher for Ntaria (\$127) than for Ltyentye Apurte (\$113). Levels of educational participation in those 15 to 19 years is close to the same in both places. Income in both communities has increased between 2006 and 2016 to within $\$ 10$ of one another (per person/per household) with the increase having just kept up with inflation at Ntaria, while returning a slight real increase in Ltyentye Apurte. The primary difference over the ten years of CTG program governance in these communities was the reduced overcrowding at Ntaria, where new houses were built. Some houses at Ltyentye Apurte were renovated in that same period.

\section{Ntaria}

From 2010 to 2012 the Australian Government, through the Department of Families, Housing, Community Services and Indigenous Affairs (FHCSIA) commissioned participatory action research to evaluate local community governance of remote service delivery in several remote communities, including Ntaria (Hermannsburg). Through the Remote Operational Centre (ROC) and Growth Town policies of Australian and Northern Territory governments, Ntaria received focused investment in programs. Through the Closing the Gap policy (Australian Government, 2016), funds were targeted to transform Ntaria into a "town" and to accelerate the provision of services in its wider region. Under this ROC model, a Local Implementation Plan (LIP) listed the community service delivery priorities, the actions, and the service provider responsibilities for each outcome. The LIP required a Local Advisory Board (Wurla Nyinta) through which the community was to contribute to improve service coordination and delivery, and in some cases to represent themselves (the community) as the lead agency in actions.

Unlike the service agencies, Wurla Nyinta was without a service agreement or any resources to drive its actions. It was without constituted powers to negotiate beyond its community and advisory capacity, and had no access to participate in decision-making beyond the community level. Despite this, Wurla Nyinta retained local elders, youth representatives and others in a voluntary capacity (FHCSIA, 2011). Wurla Nyinta was named as lead organisation for getting children to go to school and pregnant mothers to attend clinics, to reduce smoking across the community, increase adult work attendance and improve community safety (FHCSIA, 2011).

In 2010 the local community research project, Strengthening Community Research for Remote Service Delivery, was commissioned to research the implementation of LIP priorities and service delivery at Ntaria. The aims of the research contract were threefold: to focus on what and how the priorities of the community could be served through the Ntaria Local Implementation Plan (FHCSIA, 2011); to employ and train Arrernte in a participatory action research method; and to evaluate the Remote Service Delivery implementation in Ntaria. The third aim, the local evaluation of coordinated service delivery, was rescinded by the Federal department almost before signatures dried on the contract. The work required for the first two outcomes was undertaken with a research ethical clearance from the Central Australian Human Research Ethics Committee (Flinders University in Adelaide).

The community research team identified that safe/unsafe use of vehicles, driver disqualification, drink driving and driver training at Ntaria was the most important and relevant priority to inquire about. Their rationale was that too many of their family members were in jail for preventable vehicle-related offences. A number of those offences appeared to be unavoidable given no local mechanical and repair services, despite two provisioned garage facilities in the community. In addition, members of the community had lost their lives through driving accidents related 
to speed and alcohol. The idea of a safe-driving survey tested positively with services such as health, education, police and employment brokers. The topic was relevant to CTG targets for health, economic participation, safe communities, governance, leadership and increasing the life expectancy of Aboriginal people. In other words, the research priority aligned to the Closing the Gap social governance by program framework. The Local Implementation Plan (Lovell et al., p.33, 2011) included safe driving actions as a community-led outcome:

- Less people die on the roads. In-community road safety driver training programs are provided. Ntaria community members learn safe driving practices, access driver training and acquire drivers' licences.

The research found lack of opportunity to improve, repair or maintain vehicles contributed to many preventable vehicle-related charges as the nearest service was 130 kilometres away from community. The report recommended a strategic planning process to outline how many CTG targets a local garage facility would contribute to, and to assess where the means to develop it would come from. The garage proposal linked with LIP priorities to support adult training outcomes, employment, local business development, youth diversion and community service orders, men's programs, Job Service Providers services and support, driver licence training, tourism, and preventative driver training programs for young people. At the time of writing in 2018, a visiting mechanic provides some maintenance of vehicles at one of the garage facilities every couple of weeks.

As a point of procedural ethics, some feedback back from the research commissioners (the Federal Government) with a rationale for why such a core infrastructure was or was not a priority was expected. In the face of ongoing and preventable incarceration of members of the community, and the investment of public funds in a burgeoning tourist trail running past the community, a mechanical service which was publicly accessible in a region with no competition from other such services seems like an economically viable proposition. Certainly, the impact of the situation on community health, wellbeing and safety should prompt questions of governmental process about the lack of equity, and possibly unethical disregard.

\section{Ltyentye Apurte}

Questions for research about social enterprise and community bush-medicine making came to attention at Ltyentye Apurte in 2017. A process for Participatory Action Research (PAR) coresearch was devised to map ways that customary values and the everyday use of native plant traditions intersected with aspirations of social enterprise. Women particularly were interested in community health and wellbeing outcomes, and some wanted to explore the relationship of the customary activities of bush medicine to a contemporary business activity. The research was undertaken with an ethical clearance from Charles Darwin University Human Research Ethics Committee. The researchers assessed the infrastructures available in the community possible sales points, vehicles to access plants for harvesting, and a place to produce pots of bush balm which entrepreneurs would require if developing a business model. In the process of investigating whether a supply chain could be established, and what resources were needed or available, different views of purpose, intent and value began to emerge.

Finding a common ground between the remote customary health ecology, community employment and active welfare programs, the economic flow-on from social enterprise, and determining a market's value chain is not straightforward. While the academy's ethics protocol operates as a guiding proposition, the practical activity and potential commercial outcomes from this project are being determined under ethical propositions that are driven and explored at the community/family level; at the enterprise/community level; and in some ways, at the level 
of active welfare and governance by program. Without being a defined community program, but being open to the economics of a supply chain, social enterprises outcomes meet some, but not all, of the aims that wild harvesters of native plants seek.

The relationship between customary assets - including the knowledge and plant materials used in bush-balm making - and access to niche cosmetics markets provide examples of the complexity of contemporary tradition. An initial poll found a range of different views about local production, knowledge sharing and dissemination of commercial products. These included how such products are given value and how they are exchanged. Research into regional social enterprise found that beyond these local value systems, the knowledge associated with the plants, their part in a remote inland social ecology, and the products themselves were realising a modest but significant value in the cosmetics sector.

The cosmetic market for bush balms contributes to two Aboriginal health-related agencies in Alice Springs (Akeyulerre and Purple House). Each runs specialised social enterprise programs through which they produce a range of strategically marketed commercial cosmetic products. Utilising different social enterprise models, these Aboriginal agencies returned benefit to those involved in production, which included through direct employment and in the supply of bush balms back into local communities. From the wider commercial market place their products generate a collective income for these agencies as well. The Aboriginal bush balm "niche" in the cosmetics markets capitalises on a customer base who will choose to support sustainable (native plants, locally made) and ethical (Aboriginal customary land management) products.

The impetus between Arrernte Elders and the eventual cosmetics customers is the financial flow from commerce to maintain customary priorities as well as to procure economic benefits. The process of making bush balms involves healing people and land, teaching younger generations, maintaining country. These things ensure contemporary traditions are the root of the use of customary knowledge in Aboriginal-owned commercial businesses while producing a market product with broad appeal. To work through the equivalences between these customary values and the opportunities of a niche market is essential for the wild harvesting of native plants, and for the transmission of knowledge of the plants and customs to the next generations, whose initiatives will ensure the sustainability of these customs and plants.

Access to unfettered resources are necessary for community entrepreneurs to produce and supply a wider market, and these are extremely limited within the social governance by program framework. Active welfare programs are mandatory and involve regulation of any employment or community development activity which involves a recipient of active welfare, by the agency delivering the service agreement. There is an argument here for remote communities to have access to some forms of resource that enable remote community entrepreneurs to gain economic ground with or without the auspice of an organisation. Acknowledgement from the research commissioners about findings which describe a different economic development pathway would contribute to a highly portable and useful meta-data about remote economic participation, and would acknowledge that conversations about contemporary cultural agency need to occur at sub-national and national levels.

\section{An ethical proposition}

The outcomes of Australian Government policy intervention in central Australia have been monitored against Closing the Gap targets for more than a decade (Australian Government, 2016), and they underscore a substantial level of policy failure in this region. Poor relationships with Aboriginal communities over years and generations has created a harsh backdrop against which social and cultural capital and agency are often invisible. On the other hand, there 
is a demonstrated approach to knowledge and practice that redresses cultural dissonance in research, for example through the ethic of "practical wisdom" (Bainbridge, Whiteside, \& McCalman, 2013; Flyvbjerg, 2001), and through the establishement of co-research and local priorities in remote Aboriginal communities (Judd, 2017; Lovell et al., 2012). Yet it is unclear in what circumstances the research and evaluation of positive interventions or opporuntities is enough to influence a return of benefit (and therefore resource allocation) through the highlevel systems of national Indigneous program design in ways that are meaningful and timely at the community level. Cultural dissonance is more than procedural and more than relational; it is structurally enmeshed in the highest levels of Australian governments' policy and program design, and shapes the Indigenous and non-Indigenous organisations and authorities that are funded accordingly.

As a useful mediation of the unintended or negative impacts of national frameworks, feedback to researchers about the use and portability of their findings could provide a literal understanding at a community level about how to increase the impact of the research and evaluation undertaken. That feedback could also be a unit of data and a body of meta-data which, if administered via human research ethics committees, would provision research institutions to be better able to track the impacts of research and evaluation over time, and to identify short-, mid- and longer-term trends in policy making. Ideally, insight of what program interventions can contribute to which forms of social benefit and for which communities would improve a range of service delivery outcomes and redress some of the inherent cultural dissonance and bias which contributes to the current levels of service failure in certain settings.

The protocols that underpinned the work of the HREC were conceived in western-based knowledge, language and concepts, and framed at the national level (Guillemin \& Gillam, 2004). To counter the cultural dissonance between them in the indigenous-western knowledge binary, new protocols were necessary. The aim was to ensure that researchers negotiate Indigenous Knowledge in ways that address the concerns of Aboriginal people (Dunbar \& Scrimgeour, 2017). Indigenous researchers have eloquently described the Aboriginal values that drive ethical research practices by, with and among Aboriginal populations in Australia. Recent literature reflects on Indigenous and multidisciplinary practices across the disciplines of the academy (Nakata, 2007; Nakata et al., 2012), and structural resources have been developed that inform researchers engaging Aboriginal participants and collaborators on the protocols required for ethical research (Dunbar \& Scrimgeour, 2017). In addition to health and medical research guidelines, the Aboriginal Knowledge and Intellectual Property Protocol: Community Guide (Orr et al., 2009) provides an Aboriginal community guide about the rights of communities to choose their participation (or not) in research and their rights to participate in and undertake such work.

This paper proposes that reporting back to community-level research also become an extension of the current human research ethical protocols: the aim being to regulate the current cultural dissonance that national protocols cannot discern, in a research and evaluation environment in which research commissioners are not required to explain any rationale about their uptake or not of community research findings. It is hoped a wider conversation might take place about ways to redress both cultural and geographic dissonance between urban and remote societies in Australia.

\section{Discussion}

In most social research, some form of dilemma will arise that will require refinement of research methods or instruments, or an amendment to the original ethical clearance. An iterative process of design and ethics in the Longitudinal Study of Indigenous Children in Australia 
(LSIC) identified iteration as a successful indicator of ongoing participation and of continued Informed Consent (Dunbar \& Scrimgeour, 2017). Judd (2018), on the other hand, describes the process of engaging the HREC protocol as a more emergent and relational process of discussion.

The intention of the human research ethical clearance is for a continuity between procedure and practice, to enable researchers to be ethical and on their feet in practical and responsible ways, and for committees to be satisfied that research procedures are in place, which ensure ethical public-good outcomes are achieved with transparent institutional oversight (Guillemin et al., 2012). There is a high stake in university ethics committees in providing transparent and non-partisan ethical administration of research processes. It is an issue that affects how researchers and participants, as well as other stakeholders, perceive the role of researchers, the university, and the commissioners funding research (Dunbar \& Scrimgeour, 2017; Guillemin et al., 2016; Judd, 2017).

Where Indigenous ethical research processes are most likely to be undertaken with a conversational discourse the research extends over a timeframe which allows for that. The process can include adaptations to research design to address issues of ethical concern which might arise throughout the duration of longitudinal or phased programs. These timelines are more likely for research projects that are large scale, nationally significant and produce statistically quantifiable levels of data, and/or data useful for secondary analysis (Dunbar \& Scrimgeour, 2017; Guillemin \& Gillam, 2004). Currently, much research that occurs within post-graduate, early-career and commercial research domains is short term, designed to produce findings or recommendations that report against one set of factors or one level of implementation, or are specific to one setting.

Remote Aboriginal community research is most likely to be sporadic and undertaken through short-term contracts. More value could be derived from these endeavours were the findings and decisions on uptake also contributing to a meta-level of analysis that was accessible to researchers, their institutions and the communities involved. In Ntaria, the research project's capacity to effectively feedback to government through establishing a system of local community evaluation to run as part of the local implementation of services was initially a contracted aim of the Aboriginal Community Research team. However, this was rapidly blocked at a higher level of program administration, and when evaluation did eventually come, it was without the community research teams' input and the community level of evaluation was subsumed by an evaluation of the entire program of the National Partnership Agreement.

An overview of relevant literature adds further perspective about the scope of human research undertaken with Aboriginal people in remote (and non-remote) settings. Human research requires a significant social capital investment by participants and often by researchers; this appears to be offset in part with the expectation that social good outcomes are achieved at a community or sub-group level (Dunbar \& Scrimgeour, 2017; Lovell et al., 2012). Guillemin et al. (2016) found that Aboriginal and Torres Strait Islander participants' understanding of human research ethics enhanced their commitment to participate in longitudinal research in which their personal investment counted towards a better community-level outcome. In contrast to the application of national frameworks, intersectionality describes the interaction of social structures such as race, gender, and class with the agency of a social group, and the impact of those structures on social groups and their settings (Bourdieu, 1989; Butler, 1990; Byrne \& Callaghan, 2013). Applying intersectional theory contributes to an interpretation of the cultural and geographic dissonance that is evident in research undertaken in some remote settings under the current social governance by program framework of Closing the Gap policy. The national human research ethical process in designed as iterative; yet the current national policy framework does not have transparent mechanisms for researchers and communities 
to better understand how to influence program design and delivery through research and evaluation undertaken at the community level. A system of feedback would contribute to lessening the homogeneity that drives dissonances at the national, sub-national or remote community interface.

In getting to where we now are as a nation-state, the Land Rights and Native Title Acts from the 1970s and 1980s were epitomised by discourses of hope and opportunity for a new era of Aboriginal empowerment, especially, some felt, through collaboration with industry and government to enable the extractive resource sector (mining) and other large-scale landuse developments (Rowse, 1993). Just as politicians described the benefits of assimilating, Aboriginal leaders spoke with much certainty, conviction and hope about the empowering impact that access to customary land provided through connection to spirituality, language and tradition (Dodson, 1997). The current guidelines of ethical research principles for human research can be understood similarly to the judiciaries' Land Rights and Native Title legislations (Attorney-General's Prime Minister and Cabinet, 1976; Australian Parliament, 1993). Both aim to protect and promote the equal rights of Aboriginal peoples; their cultures, traditions, languages, and lands, seas and waterways; and to guide the ways that researchers, via the academy, acknowledge Aboriginal agency in research. Neither can ensure that the nation-state addresses the roots of colonial systems which continue to shape the social governance of Aboriginal people in remote Australia, and which have little capacity to engage contemporary community cultures as knowing, authoritative and self-determining (Austin-Broos, 2001; Judd, 2018).

Locating self-determination within ethical research practice is at the heart of the academy's guidelines for ethical research with Aboriginal people (National Health and Medical Research Council [NHMRC], 2015; AIATSIS, 2012). What appears to have been missed in national guidelines for ethics is an imperative that funding commissioners are also answerable for the impact of their programs, and should share accountability under the ethical protocols by which research is governed. Austin-Broos (2001) describes such an investment in conversational discourse as crucial to local traditions and self-determination, and to ethical research and evaluation.

There would be real negotiation if Western Arrernte people could speak effectively about why community support in education and regional economic partnerships are crucial to their local traditions for reasons that go beyond concerns even of other rural Australians. Making the moves to realise this would test the mettle of any political party. It would also involve a defensible ethic. (2001, p. 198)

\section{Conclusion}

An arms-length meta-analysis of research findings, policy uptake and program implementation could ensure feedback to researchers and communities that promotes a better understanding of the rational and priorities of the current social governance by program. Such a function could operate through the existing human research ethics committee process, which is in place to ensure research is equitable and ethical. Acknowledging the intersectionality and politics of power that are entailed, an evaluation of how cultural and geographic dissonance is amplified between national and community-levels of programming seems an unlikely grant winner. The greatest vulnerability in the proposition for feedback and meta-data is whether the institutions, in their current form and with the levels of reliance on political opinion for access to funds, would be able to sustain the high degree of impartiality required to insulate the researchers' pursuit of knowledge from the more partisan priorities of research-funding commissioners. 
If resources were allowed, then remote Aboriginal community research would leverage significant social benefits through one or more factors: training and engagement of local researchers; informed change based on ethical research knowledge in a local setting; being a process in place to collect, analyse and disseminate local information; providing high quality local information for use in wider inter- or intracultural negotiations; and identifying priority issues, challenges and outcomes at the community level. Understanding why research knowledge or recommendations were or were not taken up over time could help to inform Aboriginal community research, providing information that researchers and stakeholders could use to best position their work for local outcomes.

Such feedback should, ethically speaking, strengthen the insight of the commissioners of research too, creating a public record of the return of benefits from public funds invested. As meta-data, this would help researchers to identify successful local outcomes and their causal mechanisms; better evaluate and align support to programs with sound local governance; and ensure that research knowledge was being produced and utilised with a level of transparency at all levels. This more equitable accountability of the public investment in research would shift power from the government bureaucracy and invest it in the academic institutions through which it was produced. That is a highly unlikely outcome in the current Australian social and political climate. It would require an ethic and purpose that is not apparent in our nationstate. The veil between remote communities and their contribution to knowledge that is a commoditised and marketable resource could be lifted, and the capacity to access and utilise community-level research according to our own priorities and principles enacted. What kind of local governance and national political will would it take to realise that? 


\section{References}

Attorney-General's Prime Minister and Cabinet. (1976). Aboriginal Land Rights (Northern Territory) Act 1976, by Australian Government, vol. Act No. 191 of 1976, Australasian Legal Information Institute. Retrieved from http://www.austlii.edu.au/au/legis/cth/consol_act/alrta1976444/

Austin-Broos, D. (2001). Whose ethics? Which cultural contract? Imagining Arrernte traditions today. Oceania, 71(3), 189-200.

Australian Bureau of Statistics. (2016a). Hermannsburg Census 2016 Quick Stats. Retrieved from http://www.censusdata.abs.gov.au/census_services/getproduct/census/2016/quickstat/ IARE702007?opendocument

Australian Bureau of Statistics. (2016b). Ltyentye Apurte Census 2016 Quick Stats. Retrieved from http://www.censusdata.abs.gov.au/census_services/getproduct/census/2016/quickstat/ ILOC70200102?opendocument

Australian Government. (2016). Closing the Gap Prime Minister's Report 2016. Retrieved from http:// closingthegap.dpmc.gov.au/

Australian Institute of Aboriginal Torres Strait Islander Studies (AIATSIS). (2012). Guidelines for ethical research in Australian indigenous studies, (rev. 2nd ed). Canberra: Author.

Australian Parliament. (1993). Native Title Act, by Australian Government, vol. Act No. 110 of 199, Australian Government. Retrieved from http://www.austlii.edu.au/au/legis/cth/num_act/ nta1993147/longtitle.html

Bainbridge, R., Whiteside, M., \& McCalman, J. (2013). Being, knowing, and doing: A phronetic approach to constructing grounded theory with Aboriginal Australian partners. Qualitative Health Research, 23(2), 275-288.

Bourdieu, P. (1989). Social space and symbolic power. Sociological Theory, 7(1), 14-25.

Butler, J. (1990). Lana's “Imitation": Melodramatic repetition and the gender performative. Genders, (9), $1-18$.

Byrne, D., \& Callaghan, G. (2013). Complexity theory and the social sciences: The state of the art. USA and Canada: Routledge.

Department of Families Housing Community Services and Indigenous Affairs (FHCSIA). (2011). Local Implementation Plan - Ntaria. Retieved from: http://hdl.handle.net/10070/244177

Dodson, M. (1997). Land rights and social justice. In G Yunupingu (Ed.), Our land is our life: Land rights past, present and future. 39-51. St Lucia, Qld: University of Queensland Press.

Dunbar, T., \& Scrimgeour, M. (2017). LSIC: Procedural ethics through an Indigenous ethical lens. In M. Walter, KL Martin \& G Bodkin-Andrews Indigenous Children Growing Up Strong. Palgrave Macmillan, London. Springer.

Flyvbjerg, B. (2001). Making social science matter: Why social inquiry fails and how it can succeed again. (Vol. 7), Science Technology \& Society, Cambridge, UK: Cambridge University Press.

Guillemin, M., \& Gillam, L. (2004). Ethics, reflexivity, and "ethically important moments" in research. Qualitative Inquiry, 10(2), 261-280.

Guillemin, M, Gillam, L, Rosenthal, D \& Bolitho, A 2012, 'Human research ethics committees: examining their roles and practices', Journal of Empirical Research on Human Research Ethics, vol. 7, no. 3, pp. 38-49.

Guillemin, M., Gillam, L., Barnard, E., Stewart, P., Walker, H., \& Rosenthal, D. (2016). "We're checking them out": Indigenous and non-Indigenous research participants' accounts of deciding to be involved in research. International Journal for Equity in Health, 15(1), 8-18. 
Janke, T., Pitt, A., \& Herborn, D. (2013). Law way: Indigenous business and the law. Retrieved from http://www.iba.gov.au/wp-content/uploads/2013/09/Law-Way_-Indigenous-business-and-thelaw-booklet.pdf

Judd, B. (2017). Sporting intervention: The Northern Territory National Emergency Response and Papunya football. In E. Baehr \& B. Schmidt-Haberkamp (Eds.), 'And there'll be NO dancing': Perspectives on policies impacting Indigenous Australia since 2007, 110-127. Newcastle upon Tyne, UK: Cambridge Scholars.

Judd, B. (2018). Colonialism and race relations in remote inland Australia: Observations from the field of Australian Indigenous Studies. ab-Original: Journal of Indigenous Studies and First Nations and First Peoples' Cultures, 1(2), 214-242.

Kelly, J., Saggers, S., Taylor, K., Pearce, G., Massey, P., Bull, J., Odo, T., Thomas, J., Billycan, R., Judd, J., Reilly, S., \& Ahboo, S. (2012). "Makes you proud to be black eh?": Reflections on meaningful Indigenous research participation. International Journal for Equity in Health, 11(I), 40-48 .

Limerick, M.C., Department of the Prime Minister and Cabinet (Chapters 2), Colmar Brunton Social Research (Chapter 4), O'Brien Rich Research Group (Chapter 5), Putt, J.C. (2014). National Partnership Agreement on Remote Service Delivery Evaluation 2013. Retrieved from http://www.dpmc.gov.au/indigenous-affairs/publication/ national-partnership-agreement-remote-service-delivery-evaluation-2013.

Lovell, J. (2017). Central Australian native plant business literature and research synthesis. Adelaide: Ninit One Limited,.

Lovell, J., Armstrong, A., Inkamala, M., Lechleitner, A., \& Fisher, S. (2012). Final report: Strengthening community research in remote service delivery at Ntaria. Closing the Gap Clearing House, Ninti One Limited. Retrieved from https://www.researchgate.net/profile/Judith_Lovell/ publication/277978915_Final_Report_Strengthening_Community_Research_in_Remote_Service_ Delivery_at_Ntaria/links/5577f17d08aeb6d8c01ceaec.pdf

Martin, K., \& Mirraboopa, B. (2003). Ways of knowing, being and doing: A theoretical framework and methods for indigenous and indigenist re-search. Journal of Australian Studies, 27(76), 203-214.

Nakata, M. (2007). The cultural interface. The Australian Journal of Indigenous Education, 36(5), 2-14.

Nakata, M., Nakata, V., Keech, S., \& Bolt, R. (2012). Decolonial goals and pedagogies for Indigenous studies. Decolonization: Indigeneity, Education \& Society, 1(1), 120-140.

National Health and Medical Research Council, Commonwealth of Australia. (2015). National Statement on Ethical Conduct in Human Research 2007. NHMRC. Retrieved from www.nhmrc.gov.au/ guidelines/publications/e72.

National Health and Medical Research Council 2003, Values and Ethics - Guidelines for Ethical Conduct in Aboriginal and Torres Strait Islander Health Research. Retrieved from <http://www.nhmrc.gov. au/_files_nhmrc/publications/attachments/e52.pdf

Orr, M., Kenny, P., Gorey, I., Mir, A., Cox, E., Wilson, J., \& Ninti One. (2009). Aboriginal knowledge and intellectual property protocol: Community guide. Alice Springs: Desert Knowledge Cooperative Research Centre.

Rowse, T. (1993). How we got a native title act. The Australian Quarterly, 65(4), 110-132.

Shannon, C., Shibasaki, S. \& Australian Health Ethics Committee, (2005). Keeping research on track: A guide for Aboriginal and Torres Strait Islander peoples about health research ethics, by National Health and Medical Research Council (NHMRC) Australian Government. Retrieved from https:// www.nhmrc.gov.au/_files_nhmrc/publications/attachments/e65.pdf

Sulkunen, P. (2008). Social research and social practice in post-positivist society. The Sage handbook of social research methods (pp. 68-80), Los Angeles, London, New Delhi, Singapore: Sage Publications. 
Wadsworth, Y. (2011). Building in research and evaluation: Human inquiry for living systems. Hawthorn , Vic: Action Research Press and Allen \& Unwin.

Whiteford, P. (2015). Tales of Robin Hood (Part 1): Welfare myths and realities in the United Kingdom and Australia. Australian Review of Public Affairs. Retrieved from http://www.australianreview.net/ digest/2015/09/whiteford.html 